\title{
O enfrentamento do enfermeiro na liderança em Saúde Coletiva: Um relato de experiência
}

\author{
The course of the nurse in leadership in Collective Health: A report of experience \\ El enfrentamiento del enfermero en el liderazgo en Salud Colectiva: Un relato de \\ experiencia
}

Simone Maria de Araujo Maia ${ }^{1 *}$, Cristiane da Costa Oliveira Claro², Juliana Ramos Albuquerque ${ }^{2}$, Monique Vieira da Luz Carvalho², Núbia Valeria Cruz Vieira' ${ }^{2}$, Paola Teixeira Vidal ${ }^{2}$, Paula da Silva Carvalho', Paula Marcelle Magre da Silva Rangel'2, Thiago de Azevedo Figueiredo².

\section{RESUMO}

Objetivos: O estudo objetivou descrever a experiência vivenciada pelos discentes de enfermagem no enfrentamento do enfermeiro na liderança em saúde coletiva e desenvolver contribuições práticas em seu processo de trabalho. Resultado: Conseguiu-se perceber a relevância de duas categorias. Na primeira descreveremos a caracterização dos participantes da pesquisa e os tipos de liderança. $\mathrm{Na}$ segunda a contribuição prática em seu processo de trabalho. Considerações Finais: Proporcionou resultados relevantes para melhoria no processo de trabalho dos envolvidos. Aos acadêmicos de enfermagem foi imprescindível perceber o papel mediador do enfermeiro frente ao seu perfil de liderança.

Descritores: Liderança, Estratégia saúde da família, Enfermeiros.

\section{ABSTRACT}

Objectives: This study aimed to describe the experience experienced by nursing students in confronting nurses in leadership in collective health and to develop practical contributions in their work process. Result: It was possible to perceive the relevance of two categories. In the first one we will describe the characterization of the research participants and the types of leadership. In the second the practical contribution in your work process. Final Considerations: Provided relevant results for improvement in the work process of those involved. It was imperative for nurses to understand the mediating role of nurses in face of their leadership profile.

Descriptors: Leadership, Family health strategy, Nurses.

\section{RESUMEN}

Objetivos: El estudio objetivó describir la experiencia vivenciada por los discentes de enfermería en el enfrentamiento del enfermero en el liderazgo en salud colectiva y desarrollar contribuciones prácticas en su proceso de trabajo. Resultado: Se logró percibir la relevancia de dos categorías. En la primera describiremos la caracterización de los participantes de la investigación y los tipos de liderazgo. En la segunda la contribución práctica en su proceso de trabajo. Consideraciones finales: Proporcionó resultados relevantes para la mejora en el proceso de trabajo de los involucrados. A los académicos de enfermería fue imprescindible percibir el papel mediador del enfermero frente a su perfil de liderazgo.

Descriptores: Liderazgo, Estrategia de salud de la familia, Enfermeras.

1Docente no Centro Universitário Anhanguera de Niterói, Rio de Janeiro. E-mail: simoneamaia@yahoo.com.br 2Graduanda em Enfermagem, Centro Universitário Anhanguera de Niterói, Rio de Janeiro. 


\section{INTRODUÇÃO}

O conceito de liderança nos leva a compreensão de uma habilidade possível de ser desenvolvida por profissionais no mercado de trabalho. Constitui uma ferramenta indispensável na resolutividade de cada processo das atividades cotidianas. Sendo eles dimensionamento de pessoal, organização das tarefas além de ser utilizada para influenciar as pessoas na mudança de condutas e melhoria do trabalho (COSTA et al, 2017).

Na busca pelo conceito de saúde coletiva, foi identificado como campo de conhecimento e âmbito próprio de práticas interdisciplinares, epidemiológicas e ciências sociais em saúde (OSMO e SCHRAIBER, 2015). A estratégia saúde da família dentro do sistema único de saúde (SUS) nos permite entender uma remodelação no cuidado do indivíduo de forma holística (BRASIL, 2017).

A percepção do enfermeiro não deve ser somente na doença, mas o seu olhar diferenciado ao usuário e sua família. O conhecimento da relevância situacional do local em que ele vive permite que o profissional conduza as intervenções resolutivas frente as vulnerabilidades classificadas.

O enfermeiro atua como líder em processos de trabalho e desenvolve atividades em parceria com a equipe composta pelos Agentes Comunitários de Saúde (ACS), técnico de enfermagem e articula ações com o Núcleo de Apoio em Saúde da Família (NASF). Ele tem um papel não apenas de líder, mas de mediador nas relações interpessoais (LANZONI e MEIRELLES, 2011).

Para o trabalho em saúde, é fundamental refletir na unidade dos saberes, no respeito às especificidades das profissões da saúde e, principalmente, apostar na troca entre os profissionais, pois por meio da comunicação pode-se contribuir coma as novas formas de trabalho. Contudo, a comunicação ineficaz traz desgastes nas relações e até agressões (DUARTE e BOECK, 2015).

Para Minayo (2012), nem todo gestor é um líder preparado. Traz a gerência como um ponto crítico e remete as individualidades do cargo ressaltando o estresse ocasionado pelas centrais de gestão, influência de mudanças gerenciais, burocracias em geral, o excesso de demandas cadastradas e fora de área, gerenciamento das equipes onde sustenta a eficiência técnica e política na promoção, prevenção e recuperação da saúde do usuário e sua família no seu processo de trabalho diário.

Ainda de acordo com Duarte e Boeck (2015), na área da saúde, o profissional pode se deparar com a falta de cooperação, processos de trabalho rigidamente hierarquizadas, a disparidade social entre os membros da equipe e a alta rotatividade dos profissionais são os principais desafios para a efetividade do trabalho integrado e qualidade assistência adequada.

Frente a um panorama histórico para atender a proposta de consolidação do SUS, através da transformação das demandas práticas dos profissionais, o Ministério da Saúde (MS) (2004) regulamenta a Portaria no 198/GM, a Política de Educação Permanente em Saúde (EPS): com o objetivo de transformar e qualificar as ações e serviços de saúde.

No contexto de transformação e capacitação dos trabalhadores de saúde que o profissional enfermeiro se insere numa dimensão de peculiaridades cujo desafio é contribuir para a prestação de cuidados integrais de saúde a indivíduos e coletividades (PAULINO et al, 2012).

Assim é atribuído ao enfermeiro a supervisão, coordenação e realização das atividades de EPS nesse cenário. O enfermeiro desenvolve papel essencial na Estratégia de Saúde da Família (ESF) e contribui diretamente para a efetivação da política de saúde pública (PAULINO et al, 2012).

A EPS possui uma estratégia metodológica de educação problematizadora a partir de vivências dos profissionais, com vistas a mudanças organizacionais das práticas de saúde, na perspectiva da integralidade, do trabalho em equipe, da cidadania e da autonomia dos trabalhadores e usuários (COUTINHO, 2014).

O estudo objetivou descrever a experiência vivenciada pelos discentes de enfermagem no enfrentamento do enfermeiro na liderança em saúde coletiva e desenvolver contribuições práticas em seu processo de trabalho. 


\section{MÉTODO}

Trata-se de um estudo descritivo, do tipo relato de experiência, de abordagem qualitativa. Tiveram como questão norteadora o envolvimento na liderança e nas práticas gerenciais pelos graduandos em enfermagem do Centro Universitário Anhanguera de Niterói, do décimo período. Como requisito do estágio supervisionado em saúde coletiva, fundamentado pelo plano de ensino aprendizagem e direcionado pelo regulamento de estágio da instituição de ensino. O cenário foi uma unidade básica de saúde localizado no município da região metropolitana II, Rio de Janeiro, Brasil. No período de 14/08/2018 a 05/10/2018.

\section{RELATO DE EXPERIÊNCIA}

O resultado foi realizado através de uma análise sucinta das atividades vivenciadas pelos acadêmicos durante o estágio supervisionado. Conseguiu-se perceber a relevância de duas categorias. Na primeira descreveremos a caracterização dos participantes da pesquisa e os tipos de liderança. Na segunda a contribuição prática em seu processo de trabalho.

\section{O enfermeiro e a liderança situacional}

Percebeu-se o papel fundamental do profissional enfermeiro enquanto líder da equipe e o gestor da unidade. Na chegada à unidade o enfermeiro gestor e o líder de equipe realizam as checagens em parceria: checa a equipe presente, registra no livro de ordem e ocorrências, confirma escala, observa agenda e cardápio de atendimentos e ações do dia. Além de organizar a demanda situacional.

Muitas demandas no decorrer do dia foram vivenciadas pelos acadêmicos de enfermagem foram elas: busca ativa, gerenciamento de conflitos, dimensionamento de pessoal, acolhimento e classificação das vulnerabilidades dos usuários cadastrados ou fora de área, procedimentos de enfermagem, reunião e treinamento da equipe, melhoria no fluxo de atendimento, consulta de enfermagem, campanha, tomada de decisões, palestras, sala de espera, ações multiprofissionais, apresentação de novas propostas para a equipe, preenchimento de notificações, diagnóstico situacional da área de unidade de saúde (COSTA et al, 2015).

Além disso os alunos em questão também tiveram oportunidade de serem líderes por dois dias desenvolvendo as tarefas direcionadas pela professora de estágio. Conseguiram desenvolver dentro do seu perfil de liderança, tiveram autonomia na divisão das tarefas segundo o plano de ensino aprendizagem e bibliografias científicas. No final de cada dia tinham um feedback da professora quanto ao desempenho positivo e a evolução a ser conquistada. Atividade era pontuada de acordo com a proatividade, a ética e relação interpessoal entre os seus colegas de estágio.

De acordo com o estudo de Duarte e Papa (2011), a atribuição do líder situacional é contribuir com os participantes dentro das estratégias estabelecidas. Podendo desenvolver as habilidades dos envolvidos, estimulando a autoestima e automotivação. Além de apresentar-se com habilidades essenciais na avaliação de diagnóstico, flexibilidade e parceria na prática de sua produção mútua. No desenvolvimento dessas práticas percebe-se que nem sempre existe o domínio teórico do conceito de liderança situacional. Mesmo assim o líder apresenta características eficientes em suas condutas.

\section{Contribuição prática em seu processo de trabalho}

A ESF apresenta-se como um modelo inovador, fundamentado em um quadro ético respeitando padrões sociais e culturais. Permitindo a partir daí a efetivação de ações de promoção à saúde através da educação em saúde aplicados pelos colaboradores que a integram. A aplicabilidade dessas ações coletivas, proporcionam reflexões eficazes para os usuários quanto ao seu processo saúde-doença. E quanto a equipe que se disponibiliza a atuar nessas ações, consegue gerar aos seus gestores, melhores resultados além de se sentirem mais motivados em suas atividades diárias (DONADUZZI et al, 2009).

O enfermeiro enquanto facilitador e no exercício de sua liderança desenvolve habilidades que incluem a capacidade de perceber o que está acontecendo com todos os envolvidos dentro de suas atividades laborais, 
motiva ações criativas de sua equipe, toma decisões moderadas, além de identificar e resolver conflitos (AMTHAUER et al, 2018).

Fundamentando a nossa contribuição, desenvolvemos estratégias facilitadoras no processo de trabalho e aumento das atividades coletivas. A hipótese que acreditamos era que profissionais motivados iriam ter melhoras na sua qualidade de vida e em suas atividades laborais.

As atividades foram autorizadas pela coordenação geral da unidade e fundamentada no plano de ensino aprendizagem da instituição de ensino.

Num primeiro momento procedemos com o planejamento: a liderança era de uma acadêmica e professora onde delimitou temas e parcerias. Utilizamos como ferramenta a comunicação efetiva com os ACS, enfermeiras da unidade e o NASF. Elaborou-se atividades de educação em saúde em todos os dias durante o mês de setembro com seguintes temas abordados: tabagismo, fluxograma de atendimento ao adolescente, saúde da criança, da mulher, do homem, idoso, alimentação saudável, Hiperdia, prevenção ao suicídio, depressão, acolhimento, classificação de risco, primeiros socorros, aleitamento materno, cuidados com recém-nato, grupos de convivência, descarte de resíduos em saúde, prevenção de problemas cardíacos. Público alvo foram divididos conforme a abordagem agendada para o dia: enfermeiros, técnicos de enfermagem, recepcionistas, auxiliar de serviços gerais, NASF e usuários.

Ludicamente chamamos essas ações de "missão possível" todos os acadêmicos deveriam atingir o objetivo que era realizar a ação coletiva com seus respectivos registros.

Continuamos e traçamos um outro objetivo que era motivar as enfermeiras e os ACS a participarem juntamente com os acadêmicos em todas essas atividades, daí receberia em troca a produção da atividade coletiva preenchida, pois a unidade tinha mais de uma equipe ESF, com isso aconteceria um rodízio, chamamos esse momento de "missão difícil" devido a demanda atendida pela equipe.

Para finalizar, a estratégia utilizada foi da "missão impossível", a equipe deveria em parceria com o acadêmico entregar a produção mensal impreterivelmente no primeiro dia proposto pela coordenação geral ou antes.

Todos os objetivos das dinâmicas foram atingidos. E a "brincadeira" se tornou algo motivador para todos os envolvidos. Desde a gestão, usuários e principalmente a equipe da unidade e o NASF.

\section{CONSIDERAÇÕES FINAIS}

Os objetivos do estudo foram alcançados. Descrevemos a experiência vivenciada pelos discentes de enfermagem no enfrentamento do enfermeiro na liderança em saúde coletiva e desenvolvemos contribuições práticas em seu processo de trabalho. A pesquisa evidenciou a atuação do enfermeiro em sua liderança em todos os cuidados diretos e indiretos. O registro terá uma contribuição para o ensino e a prática organizacional do enfermeiro, sua equipe e futuros trabalhos científicos. Proporcionou resultados relevantes para melhoria no processo de trabalho dos envolvidos. Aos acadêmicos de enfermagem foi imprescindível perceber o papel mediador do enfermeiro frente ao seu perfil de liderança. $O$ desenvolvimento das produções, sendo elas palestras, salas de espera, treinamento e acolhimento aos colaboradores possibilitou aproximação do enfermeiro com os acadêmicos e o NASF onde em parceria contribuíram para melhores resultados e satisfação dos sujeitos envolvidos, principalmente dos usuários.

\section{REFERÊNCIAS}

1. AMTHAUER C, VICCARI K, SOUZA FTD et al. Gestão e gerenciamento de enfermagem: desafios e dificuldades enfrentados na estratégia de saúde da família. Anuário Pesquisa e Extensão Unoesc São Miguel do Oeste, v. 3, p. 18977, 2018.

2. BRASIL. Ministério da Saúde. Portaria no 198/GM/MS. Política de Educação em Saúde como estratégia do SUS para a formação e o desenvolvimento de trabalhadores para o setor. Brasília (DF): MS;2004.14p. 
3. BRASIL. Ministério da Saúde. Secretaria de Atenção à Saúde. Departamento de Atenção Básica. Política Nacional de Atenção Básica. Brasília: Ministério da Saúde; 2017.

4. COSTA EMZ, PERES AM, BERNARDINO E et al. Estilos de liderança dos enfermeiros que atuam na estratégia de saúde da família. Cienc Cuid Saude 2015 Jan/Mar; 14(1):962-969.

5. COSTA SD, SILVA PL, GONÇALVES RP et al. O exercício da liderança e seus desafios na prática do Enfermeiro. JMPHC 2017; 8(1):49-65.

6. COUTINHO CP. Metodologia de investigação em ciências sociais e humanas. Leya, 2014.

7. DONADUZZI, JC. Ações educativas de enfermeiras em estratégias de saúde da família. Dissertação (Mestrado em Enfermagem) - Universidade Federal de Santa Maria, Santa Maria, 2009.

8. DUARTE GA, PAPA AC. A utilização da liderança situacional como diferencial estratégico para as organizações contemporâneas. Rev. Adm., UFSM, Santa Maria, v. 4, n. 3, p. 364-377set./dez. 2011.

9. DUARTE MLC, BOECK JN. Trab. Educ. Saúde, Rio de Janeiro, v. 13 n. 3, p. 709-720, set./dez. 2015.

10. LANZONI GMM, MEIRELLES BHS. Liderança do enfermeiro: uma revisão integrativa da literatura. Rev. LatinoAm. enfermagem [Internet]. maio-jun 2011.

11. MINAYO MCS. Análise qualitativa: teoria, passos e fidedignidade. Ciênc. saúde coletiva, Rio de Janeiro, v. 17, n. 3, p. 621-626, Mar. 2012.

12. OSMO A, SCHRAIBER LB. Saúde Soc. São Paulo, v.24, supl.1, p.205-218, 2015.

13. PAULINO VCP, BEZERRA ALQ, BRANQUINHO NCSS. Ações de educação permanente no contexto da estratégia saúde da família. Enfermagem Uerj, vol. 20, no. 3, 2012, p. 368+. 